\title{
A cross-sectional study on patterns, motivating factors and barriers for physical activity among undergraduate medical students
}

$\pi$
0
0
$\frac{\pi}{4}$
0
0

Harsha Kumar HN, Neha Ramakrishnan, Mayur Chandrashekar, Arpitha Kodihalli Jayaramegowda, Mohit Kadian, Vikas Chauhan

Department of Community Medicine, Kasturba Medical College, Mangalore, Karnataka, India

Address for the Correspondence:

Dr. Harsha Kumar HN, Department of Community Medicine, Kasturba Medical College, Manipal University, Near Hampanakatta, Mangalore - 575 001, Karnataka, India. E-mail: hnkswamy@gmail.com

\begin{tabular}{|l|}
\hline Access this article online \\
\hline Website: www.jmedph.org \\
\hline DOI: $10.4103 / 2230-8598.144115$ \\
\hline Quick response code: \\
\hline
\end{tabular}

Introduction: There is little published information exploring the perceptions and physical activity patterns among undergraduate medical students in our country. So this study was conducted with the following objectives: 1 . To assess the perceptions about knowledge regarding physical activities among undergraduate medical students; 2. To assess their self-reported physical activity practices. Materials and Methods:This cross sectional study was conducted in Kasturba Medical College, Mangalore from $12^{\text {th }}$ to $30^{\text {th }}$ April, 2012. A total number of 427 students were chosen at by using the formula for infinite population. Tools: 1 . A semi-structured questionnaire to know perceptions, barriers, and practices about physical activity; 2 . Physical activity was assessed using International Physical Activity Questionnaire (IPAQ). Analysis was done by using SPSS version 11. Significance of differences across various levels of physical activity between different age-groups and gender were made by chi square test. Results: 376 students participated. Majority of them had high physical activity $(54.75 \%)$. Knowledge was poor about prevention of diabetes $(68.9 \%)$, stroke $(61.6 \%)$, and osteoporosis $(33.8 \%)$. Majority $(82.4 \%)$ of them perceived healthrelated benefits of physical activity as motivating factors rather than prevention of chronic noncommunicable diseases. Most of them (72.3\%) have enrolled in life style modification activities like yoga, going to gymnasium, etc. Conclusion: Most of the students fall into moderate physical activity group. Health-related benefits were the driving force for doing physical activity.

Key words: Barriers, medical students, motivating factors, physical activity patterns

\section{INTRODUCTION}

Adequate physical activity is very essential in order to have good health. Chronic disease is likely to be the primary disease cluster in India in the future. ${ }^{[1]}$ Physical inactivity is an important risk factor for the development of several chronic diseases including coronary artery disease, hypertension, diabetes, cancers, obesity, and osteoporosis. ${ }^{[2,3]}$ This mainly occurs due to the changing lifestyles of people.

In an academically demanding environment of college, students tend to do less physical activity. ${ }^{[4]}$ One published study conducted on junior doctors from India did not explore the knowledge about physical activity or patterns of physical activity. ${ }^{[5]}$ Another published from India which reported the patterns of physical activity did not explore if any students made a attempt change their lifestyle..$^{\left[{ }^{[6]}\right.} \mathrm{A}$ comprehensive approach which explores various aspects would enhance the understanding. So this study was conducted with the objectives:

1. To assess the perceptions and knowledge regarding physical activities;

2. To assess the pattern of physical activity;

3. Barriers and motivating factors for physical activity among undergraduate medical students.

\section{MATERIALS AND METHODS}

\section{Study design}

This is a questionnaire based Cross-sectional study. 


\section{Study setting}

Kasturba Medical College, Mangalore, South India.

\section{Study duration}

This study was conducted in the Month of April 2012.

\section{Study population}

Undergraduate medical students of $\mathrm{KMC}\left(1^{\text {st }}\right.$ and $2^{\text {nd }}$ year MBBS students), Mangalore. Inclusion criteria: All undergraduates who were present in the classrooms and willing to participate were included in the study. Those who were not willing were excluded.

\section{Sample size}

Assuming that at least $50 \%$ of the students would undertake one or the other kind of physical activity, for $95 \%$ confidence interval, $85 \%$ power, and $10 \%$ non-response, the sample size came to be 427 .

\section{Sampling}

Non-random sampling. The students who met the study criteria as mentioned above were considered.

\section{Study instruments}

1. A semi structured questionnaire was devised to collect the following components of information from the study population:

a. Characteristics of study subjects like age, gender, and semester;

b. Perceptions and barriers about physical activity; and

c. Physical activity practices measured by International Physical Activity Questionnaire (IPAQ). $\cdot^{[7]}$

2. $\operatorname{IPAQ}^{[7]}$ :

a. The development of an international measure for physical activity commenced in Geneva in 1998;

b. This questionnaire is devised for a 15-69 age group;

c. There are 2 forms - short and long. The short form was used in our study as it was more appropriate for younger individuals; and

d. The short version has seven questions, which enquires about the time spent in being physically active in last 7 days. Physical activity is graded as mentioned below.

\section{Operational definitions}

A. Physical activities are activities where there are movements which increase heart rate above its resting rate, whether it is done for pleasure, work or transportation. ${ }^{[7]}$

B. Grades of physical activity:

1. Low: is the lowest level of physical activity. Those individuals who do not meet criteria for categories 2 or 3 are considered low/inactive.

2. Moderate: Any one of the following 3 criteria:

a. 3 or more days of vigorous activity of at least 20 minutes per day or b. Five or more days of moderate-intensity activity or walking of at least 30 minutes per day or

c. Five or more days of any combination of walking, moderate-intensity or vigorous intensity activities achieving a minimum of at least $600 \mathrm{~min} /$ week.

3. High: Any one of the following 2 criteria:

a. vigorous-intensity activity on at least 3 days and accumulating at least 1500 minutes/week or

b. 7 or more days of any combination of walking, moderate-intensity or vigorous intensity activities achieving a minimum of at least 3000 minutes/week. ${ }^{[7]}$

\section{Data collection}

Institutional Ethics Committee approval was sought. Permission was obtained from the Dean for approaching the students in the classrooms. The purpose of the study was explained. Questionnaires along with attached written informed consent forms were distributed to them. A period of 10 minutes was given to fill the forms. Filled forms were collected. Inappropriately filled forms were excluded from data analysis.

\section{Data analysis}

The data was analyzed using SPSS ver.12.0. Results are presented as proportions in tables. Chi-square test was applied to know if the observed differences are statistically significant a $P \leq 0.05$ was considered significant.

\section{RESULTS}

A total of 376 students responded to our study which was less than 427 , giving us a non-response rate of $11.94 \%$. The proportion of females $(52.4 \%)$ was slightly higher than males (47.6\%). The agegroup distribution of students is as follows: $16-18$ (24.2\%), 19-21 $(72.3 \%), 22-24(3.5 \%)$.

The perceived benefits of physical activity are shown in Table 1. The reason for doing physical activity was for gaining health-related benefits rather than prevention of chronic diseases [Table 2]. The pattern of physical activity is given in Table 3. Sports related activities were the most common type. Climbing the stairs was preferred to taking the lift.

High physical activity was more common. This is cross-tabulated with gender and semester which are presented in Table 4. The proportion of females in high physical activity category is more than males.

\section{DISCUSSION}

\section{Grading of physical activity}

Majority of the students fall in to the high physical activity group followed by moderate activity. Using a different scale, Bannerjee et al., found that less proportion undertook vigorous physical activity. ${ }^{[6]}$ We do not have comparable results about lifestyle modification. Majority of the students enrolled in to yoga classes, in addition to 


\begin{tabular}{lc} 
Table 1: Knowledge and perception about benefits \\
of physical activity $(\boldsymbol{n}=\mathbf{3 7 6})$ \\
\hline Perception & $\boldsymbol{N}(\%)$ \\
\hline Physical activity helps in prevention of & \\
Obesity & $341(90.7)$ \\
Coronary artery disease & $317(84.3)$ \\
Hypertension & $302(80.3)$ \\
Diabetes & $259(68.9)$ \\
Stroke & $194(51.6)$ \\
Osteoporosis & $127(33.8)$ \\
Others & $13(3.46)$ \\
Others like ( $n=13)$ & \\
To get good sleep & $5(38.5)$ \\
Avoid stress & $4(30.8)$ \\
To avoid depression & $4(30.8)$ \\
Perceived benefits of physical activity & \\
Keeps me fresh & $310(82.4)$ \\
To burn excess calories & $280(74.5)$ \\
Reduce stress & $253(67.3)$ \\
Improves my memory & $176(46.8)$ \\
Others & $7(1.9)$ \\
Others like ( $n=7)$ & \\
Better sleep & $3(42.9)$ \\
Keeps me fit & $4(57.1)$ \\
Like to do physical activity & \\
Yes & $328(87.2)$ \\
No & $45(12)$ \\
No response & $3(0.8)$ \\
\hline
\end{tabular}

\begin{tabular}{lc}
\multicolumn{2}{l}{ Table 2: Practice and motivation for physical activity } \\
\hline Practice & $\boldsymbol{N}(\%)$ \\
\hline If no, reasons & $28(7.4)$ \\
No time & $17(4.5)$ \\
Affect studies & $6(1.6)$ \\
No space & $8(2.13)$ \\
No response & \\
Enrolled for Physical Activity & $272(72.3)$ \\
Yes & $32(8.5)$ \\
No & $72(19.1)$ \\
Don't know/not sure & \\
If yes, reasons ( $n=72)$ & $24(33.3)$ \\
Burn calories & $22(30.5)$ \\
Mental peace & $15(20.8)$ \\
Increases stamina & $11(15.3)$ \\
Keeps me fit & \\
Motivation & $305(81.1)$ \\
To be Fit and healthy & $263(69.9)$ \\
To Reduce Weight & $163(43.4)$ \\
To Increase Muscle mass & $159(42.3)$ \\
To increase Flexibility and strength &
\end{tabular}

physical activity. This would reduce the risks of chronic diseases in the long run.

\section{Motivation and barriers}

Majority of the students liked to do physical activity. Perceived benefits of physical activity and their knowledge are good among

\begin{tabular}{lc}
$\begin{array}{l}\text { Table 3: Pattern and duration of physical activity } \\
(\boldsymbol{n}=376)\end{array}$ \\
\hline Pattern and duration & $\boldsymbol{N}(\%)$ \\
\hline Playing games & $209(55.6)$ \\
Jogging & $142(37.8)$ \\
Swimming & $141(37.5)$ \\
Cycling & $121(32.2)$ \\
Gym & $117(31.1)$ \\
Others & $37(9.8)$ \\
Others like $(n=37)$ & \\
Skipping & $11(29.73)$ \\
Dancing & $9(24.32)$ \\
Aerobics & $9(24.32)$ \\
Exercise & $8(21.62)$ \\
Duration (Years) & \\
$<1$ & $78(20.7)$ \\
$1-2$ & $72(19.1)$ \\
$2-5$ & $69(18.4)$ \\
$5-10$ & $110(29.3)$ \\
No response & $47(12.5)$ \\
\hline
\end{tabular}

medical students. Most of the students have reported health-related benefits as the reason for doing physical activity. Certain students do it to get good sleep and to avoid stress and depression. Even their motivation was for health-related benefits rather than prevention of chronic diseases. Bharathi et al., reported that older adults performed household chores to a greater extent than the younger individuals who spent more time on their hobbies. ${ }^{[8]}$ Rees et al., have reported that physical activity among young adults serves to show off their skills, enjoyment and using exercise as a way of relieving stress. ${ }^{[9]}$ Our study population consists of younger individuals. This explains the pattern of physical which is mainly sport related which can be attributed to younger age.

\section{Gender differences}

Gender differences were statistically significant but the differences based on semester were not. U.S. Department of health and human services has reported that, males are more likely than females to participate in vigorous physical activity, strengthening activities, and walking or bicycling. ${ }^{[10]}$ We found that higher proportion of females had high physical activity, and the differences were statistically significant. Age-group of respondents in our study (18+ years) was higher than the reported from US (12-21 years). Besides the study population consisted of medical undergraduates as compared to younger students from US which could explain the differences.

\section{Limitations}

There are some limitations. The non-response rate was slightly higher $(11.94 \%)$ than what we anticipated. But the response rates observed in our study was higher than those reported by others. ${ }^{[8,11]}$ We cannot rule out response bias as it is a questionnaire based study. 


\begin{tabular}{|c|c|c|c|c|c|c|}
\hline \multirow[t]{2}{*}{ Types } & \multicolumn{2}{|c|}{ Gender } & \multirow[t]{2}{*}{ Chi square $(P)$} & \multicolumn{2}{|c|}{ Semester } & \multirow{2}{*}{ Chi square $(P)$} \\
\hline & Males (\%) & Females (\%) & & $2^{\text {nd }}(\%)$ & $4^{\text {th }}(\%)$ & \\
\hline Low $(n=100)$ & $61(61)$ & 39 (39) & & $63(63)$ & $37(37)$ & \\
\hline Moderate $(n=121)$ & $51(42.15)$ & $70(57.85)$ & 8.56 & $60(49.6)$ & $61(50.4)$ & 4.37 \\
\hline High $(n=211)$ & $98(46.44)$ & $113(53.55)$ & $(0.01)$ & $111(52.61)$ & $100(47.39)$ & $(0.11)$ \\
\hline
\end{tabular}

\section{CONCLUSION}

Most of the students fall into moderate physical activity group. Health-related benefits were the driving force for doing physical activity.

\section{ACKNOWLEDGEMENTS}

We express our hearty gratitude to the Department of Community Medicine and the students of Kasturba Medical College, Mangalore who took part in our study.

\section{REFERENCES}

1. World Health Organization. The World Health Report- Life in the 21st century: A vision for all. Geneva; 1998.

2. Blair SN, Kohl HW, Gordon NF, Paffenbarger RS Jr. How much physical activity is good for health? Annu Rev Public Health 1992;13:99-126.

3. Fletcher GF, Balady G, Blair SN, Blumenthal J, Casperson C, Chaitman B, et al. Statement on exercise: Benefits and recommendations for physical activity programs for all Americans. A statement for health professionals by the Committee on Exercise and and Cardiac Rehabilitation of the Council on Clinical Cardiology, American Heart Association. Circulation 1996;94:857-62.

4. Sajwani RA, Shoukat S, Raza R, Shiekh MM, Rashid Q, Siddique MS, et al. Knowledge and practice of healthy lifestyle and dietary habits in medical and non-medical students of Karachi, Pakistan. J Pak Med Assoc 2009;59:650-5.
5. Rao CR, Darshan B, Das N, Rajan V, Bhogun M, Gupta A. Practice of physical activity among future doctors: A cross sectional analysis. Int $\mathrm{J}$ Prev Med 2012;3:365-9.

6. Banerjee A, Khatri S. A study of physical activity habits of young adults. Indian J Community Med 2010;35:450-1.

7. Ekelund U, Sepp H, Brage S, Becker W, Jakes R, Hennings M, et al. Criterion related to the last 7-day, short form of the International Physical Activity Questionnaire in Swedish adults. Public Health Nutr 2006;9:258-65.

8. Bharathi AV, Sandhya N, Vaz M. The development and characteristics of a physical activity questionnaire for epidemiological studies in urban middle class Indians. Indian J Med Res 2000;111:95-102.

9. Rees R, Kavanagh J, Harden A, Shepherd J, Brunton G, Oliver S, et al. Young people and physical activity: A systematic review matching their views to effective interventions. Health Educ Res 2006;21:806-25.

10. U.S. Department of health and human services. Physical Activity and Health. [Online]. Available from: http://www.cdc.gov/nccdphp/sgr/pdf/ execsumm.pdf [Last cited on $2012 \mathrm{Apr}$ 7].

11. Topolski TD, LoGerfo J, Patrick DL, Williams B, Walwick J, Patrick MB The rapid assessment of physical activity (RAPA) among older adults. Prev Chronic Dis [Online] 2006;3:A118. Available from: http://www.cdc. gov/pcd/issues/2006/oct/06_0001.htm [Last cited on 2012 Apr 5].

How to cite this article: Kumar $\mathrm{HH}$, Ramakrishnan $\mathrm{N}$, Chandrashekar M, Jayaramegowda A, Kadian M, Chauhan V. A cross-sectional study on patterns, motivating factors and barriers for physical activity among undergraduate medical students. Int J Med Public Health 2014;4:413-6.

Source of Support: Nil, Conflict of Interest: None declared. 